\title{
OSTEOGENESIS IMPERFECTA IN SOUTHERN AFRICA: PETER BEIGHTON'S LEGACY
}

D Sillence, Professor of Genetic Medicine, The Children's Hospital at Westmead Clinical School, University of Sydney; and cofounder, Connective Tissue Dysplasia Management Service, Sydney Children's Hospital Network, Westmead, New South Wales, Australia geneticist_44@hotmail.com

When Peter Beighton (PB) took up a fellowship at the Johns Hopkins University Hospital in 1968 -1969, with Dr Victor McKusick, the 4th edition of Heritable Disorders of Connective Tissue was in preparation. ${ }^{[1]}$ PB had already concluded that EhlersDanlos syndrome (EDS) was a group of disorders with distinct but overlapping phenotypes and genotypes. ${ }^{[2]}$ McKusick $^{[1]}$ extensively acknowledged the contribution which PB had made to delineating the heterogeneity in EDSs in Chapter 6. In Chapter 7 of the same volume, McKusick reviewed the knowledge about osteogenesis imperfecta (OI) and noted that 'the exceptionally wide range of 
expressivity in OI may be but different expressions of a single type of connective tissue disorder, inherited as a Mendelian autosomal dominant disorder. However, the existence of an infrequent autosomal recessive form ... is quite certain'.

\section{Genetic heterogeneity in OI}

\section{5 - 1980}

David Danks (DMD) asked me, in 1974, to undertake a study in Victoria, Australia, to clarify the genetic relationship between perinatally lethal cases of OI and families with clearly autosomal dominant inheritance. He had preceded PB at Johns Hopkins, with Victor McKusick, by several years and was very aware of PB's contribution to unravelling the genetic heterogeneity in EDSs. Like $\mathrm{PB}$, DMD had undertaken a population study of skeletal dysplasias in Victoria, Australia (1971 - 1973), and recognised the considerable heterogeneity in these disorders. Commencing in 1975, an attempt was made to ascertain all patients with OI in Victoria, including all deaths from OI over a 30 -year period. The study proceeded along the lines of two former studies, one by Seedorf ${ }^{[3]}$ in Denmark and the other by Smars $^{[4]}$ in Sweden in 1965. We undertook careful pedigree-taking and analysis. The outcome was that in Victoria in 1977, not only had we documented a significant number of pedigrees with autosomal dominant inheritance of OI with distinctly blue sclerae but we also had many families with pedigree evidence of autosomal recessive inheritance. These included a perinatally lethal group as well as a group with progressive deformity of long bones and spine. In the face of compelling population genetic evidence for both autosomal recessively inherited forms of OI, as well as dominantly inherited types of OI, we reached the conclusion that there had to be locus heterogeneity ${ }^{[5,6]}$ The question then was how much genetic heterogeneity was there? Recent studies have characterised 22 gene loci in which mutations result in various types of OI (Table 1). ${ }^{[7,8]}$ The relative prevalence of mutations in different genes might therefore be reflected in a different prevalence of various types of OI in distinct human populations. As early as 1993, Wallis, Beighton and colleagues ${ }^{[9]}$ had concluded that autosomal recessive forms of OI were the most prevalent forms of OI in southern Africa and segregation of OI in these families was not linked to type I collagen genes. This one observation sustained future research in autosomal recessive forms of OI worldwide for a considerable period.

\section{The heritable disorders of connective tissue}

In the preface to his 1978 monograph Inherited Disorders of the Skeleton, PB noted that 'in the period 1971 - 1976 more than 1000 patients with disorders of the skeleton had been investigated in genetic clinics in southern Africa. ${ }^{\left[{ }^{[10]}\right.}$ While there were already several atlases of skeletal dysplasia such as the Atlas of Constitutional Disorders of Skeletal Development in 1974, ${ }^{[11]}$ this 1978 publication by PB represented a significant, new and different contribution that integrated the skeletal dysplasias within the broad spectrum of the heritable disorders of connective tissue (HDCT). Indeed, various meetings of the International Nosology Committee for Constitutional Disorders of the Skeleton had struggled with the need to be inclusive, particularly in the differential diagnosis of anomalies found in the skeleton. Some anomalies, e.g. Wormian bones, were found in distinctly different disorders across the spectrum of the HDCT. A joint decision was made in convening the 1986 International Nosology of Heritable Disorders of Connective Tissue to cover all those disorders that were not already in the International Skeletal Dysplasia Nomenclature and Classification, except for certain specific groups of disorders. ${ }^{[12]}$ The marked overlap between the clinical findings in the OI syndromes and other HDCT was noted. This was particularly evident in the overlap in features seen in

Table 1. The OI nomenclature 2015 - International Nomenclature Committee for Constitutional Disorders of the Skeleton

\begin{tabular}{lll}
\hline Syndrome name & Subtype & Equivalent numerical type \\
\hline Classic non-deforming OI (with blue sclerae) & 2 & 1 \\
Common variable OI (with normal sclerae) & 10 & 4 \\
OI with calcification in interosseous membranes & 1 & 5 \\
Progressively deforming OI with normal sclerae & 17 & 3 \\
Perinatally lethal OI & 5 & 2 \\
In addition, there are at least nine named syndromes and multiple premature ageing \\
disorders with overlap in phenotypic features with OI
\end{tabular}

patients with OI with features in common with the EDSs, such as marked joint hypermobility, bruising, occasional skin fragility and even rare manifestations such as elastosis perforans serpinginosa. The 1978 Inherited Disorders of the Skeleton by PB was so important because it reminded geneticists that, as a group, HDCT were not so very rare. The monograph provided information important to the 'trainee and practising doctors, with easily accessible and authoritative information about genetic aspects of their specialities'.

PB noted the genetic heterogeneity in OI with particular reference to southern Africa and, in fact, before the 1979 paper from Victoria was published, again reinforcing the potential for genetic locus heterogeneity in the OI syndromes. ${ }^{[6]}$

$\mathrm{PB}$ and Anne de Paepe convened the International Nosology of Heritable Disorders of Connective Tissue in Berlin in 1986. ${ }^{[12]}$ Already, very significant progress had been made since 1970. This Berlin nosology attempted to delineate and characterise the individual heritable disorders of connective tissue and provide key phenotypic features to differentiate each of the disorders. It was recognised at the time and had been discussed that the four broad groups of OI type were each genetically heterogeneous. Two further types of OI had been postulated (but not included in the nomenclature) an autosomal dominant disorder associated with/characterised by a tendency to hyperplastic callus (now known as OI type 5) and an X-linked form of OI which was rare and at that time defined only by its pedigree features, but now known to result from hemizygous mutations in Plastin 3 (PLS3). ${ }^{[7,13]}$

\section{6 - 1999}

In 1986, there were still some groups who questioned the genetic heterogeneity in OI and felt that sibling recurrence could be explained by germinal mosaicism, which had been recently discovered in families with sibling recurrence of OI. ${ }^{[14]}$ By the early 1990s, this was reinforced by the discovery of heterozygous mutations in siblings with perinatally lethal OI but clinically unaffected parents. $\mathrm{PB}$, on the other hand, was quite gracious and kept an open mind about autosomal recessive inheritance. He provided the full pedigrees of two families, which were incorporated in a publication on autosomal recessive OI type 3, published from our research group in 1986. ${ }^{[15]}$ These pedigrees were by no means meant to represent complete population ascertainment, but they reinforced the existence in southern Africa of 
families where the evidence strongly suggested an autosomal recessive pattern of inheritance. ${ }^{[16]}$

\section{OI with congenital joint contractures, the Bruck syndromes and endogamy}

The 1989 article with Dennis Viljoen reported five individuals with OI with a distinct phenotype comprising congenital contractures of the joints together with OI, and named this disorder Bruck syndrome (BS). ${ }^{[17]}$ In the article, the first two affected children were singletons whereas there were three children affected in family 3. These patients were from the Tswana tribal group, the Pedi tribal group and the Shona tribal group of Zimbabwe. Consanguinity was not present. However, an increased prevalence in certain indigenous groups suggested endogamy and an increased frequency of a founder mutation for BS. The report of the proband in family 3 in the paper noted that he had contractures with joint webbing at the elbow and knee joints, together with talipes equinovarus. Patient 2 in family 3 is illustrated showing quite marked joint webbing. Further families were reported but the first report of a unifying defect came from studies of telopeptide lysyl hydroxylases in the laboratory of Dr Ruud Bank. ${ }^{[18]}$ This identified missense mutations in procollagen-lysine 2-oxoglutarate 5-dioxygenase (PLOD2) in two families, one of which was from our Australian research cohort. ${ }^{[19]}$ Previous families with BS had been studied by linkage analysis and this had mapped the BS locus to an 18-centimorgan region on chromosome 17p12. However, other families were linked to 3q23-q24 and, in these, the deficiency in PLOD2 was confirmed. It was almost a further decade before the study of four inbred Turkish families from the Black Sea region located the other form of OI with congenital joint contractures, to homozygous mutations in FKBP10 that encode the RER protein FKBP65. ${ }^{[20]}$ BS type 1 mutations in $F K B P 10$ appear to be a far more common cause of BS in some populations. ${ }^{[2]}$ There is a high prevalence of BS in the Samoan Islands, where Tim Cundy was able to ascertain 17 affected individuals from 10 families homozygous for the mutation c.948dupT, p.Ile317Tyrfs ${ }^{\star} 56$. It is interesting that two families from among the SA Venda tribal group had the $c .831 \mathrm{dupC}$ mutation, which was also found in a Saudi family. ${ }^{[22]}$ The extent of carrier frequency for mutations in FKBP10 remains to be published, but what is clear is that mutations in FKBP10 may have quite a variable phenotype. Individuals have now been reported with homozygous FKBP10 mutation with only bone fragility and without congenital contractures. ${ }^{[21]}$

\section{An ocular type of OI}

Ingrid Winship, $\mathrm{PB}$ and colleagues ${ }^{[23]}$ reported an ocular form of OI with putative autosomal recessive inheritance, in 1986. The paper reported a bone fragility disorder in an inbred Indian family, with two uncles and a nephew with newborn presentation with ocular involvement and recurrent fractures commencing in mid to late childhood. The report is extensively illustrated with skeletal radiographs showing slender long bones and generalised platyspondyly. Eye findings included bilateral corneal opacities and white sclerae.

Frontali et al. ${ }^{[24]}$ in 1985 had reported siblings with osteoporosis pseudoglioma (OPPG) syndrome, in which there was severe osteoporosis and sclerae of normal hue but with progressive eye involvement. $\mathrm{PB}$ replied to the letter to the editor that the question of syndromic identity will ultimately be resolved at the molecular level. ${ }^{[25]}$

A majority of OPPG cases (typical cases) have loss of function mutations in low-density lipoprotein receptor-related protein 5 (LRP5). However, in a significant number of patients, no mutation in LRP5 was detected. In 2001, Schmidt et al. ${ }^{[2]}$ reported on a consanguineous Turkish family with almost complete platyspondyly/ vertebral flattening retinal detachment, cataract, and facial dysmorphism. A further affected child in a non-consanguineous Turkish family was reported in $2006 .{ }^{[27]}$ This child presented with fractures at birth. Recent whole exome screening in a further family with spondylo-ocular dysplasia revealed a homozygous mutation in xylose transferase 2 (XYLT2). ${ }^{[28]}$ Both siblings were identified prenatally because of the detection of widened nuchal folds. These siblings were noted to have nystagmus soon after birth and earlyonset symptomatic osteoporosis with progressive vertebral collapse (interpreted as platyspondyly, hence 'spondylodysplasia'). While vertebral findings were progressive and quite severe, requiring treatment with cyclic intravenous pamidronate, long-bone fractures were rare. During the investigations of this family, a further single case in a consanguineous family, also with generalised osteoporosis and marked vertebral flattening, was also found to be homozygous for a different mutation in XYLT2. Two of the three patients had retinal detachments. There is variability in the phenotypic features reported for the patients with a spondylo-ocular syndrome. However, it is important to note that, in addition, hearing loss and heart defects have been noted in a number of these patients.

At the present time, there is no overall review specifically dealing with the patterns of visual disability and eye pathology in OPPG v. spondylo-ocular syndrome(s). Improved phenotype/genotype correlation will be available in the future, resulting from multiple parallel sequencing for both the classic and typical OPPG and these other patients with early-onset eye involvement and progressive osteoporosis, such as this spondylo-ocular group. Spondylo-ocular is an unfortunate name for this particular syndrome as the generalised platyspondyly is thought to be due to early-onset progressive osteoporosis. In patients with homozygous $L R P$ mutations, there was a wide variety of eye involvement. Some patients were congenitally blind in both eyes, and some blind in one eye and visually impaired in the other, or moderately visually impaired in both eyes. Most adults were blind by 15 years of age and all were blind by 25 years of age. The eye findings in OPPG included isolated cataracts, retinal coloboma, Peters anomaly and unilateral eye involvement. In addition, these patients may develop severe vitreoretinal findings, including phthisis bulbi. In the few patients to date reported with a proven or with possible homozygosity for XYLT2, eye findings include early amblyopia, cataract and progress to retinal detachment in late childhood or the second decade.

The characterisation of this mutation in XYLT2 provides important biochemical and functional insight into the role of the enzymes involved in the biosynthesis of the GAG linker region. These are known as GAG linkeropathies and involve mutations which disrupt the synthesis of a tetrasaccharide - xylose-galactosegalactose-glucuronic acid, O-linked to the proteoglycan core protein. Mutations in xylose transferase 1 result in the newborn skeletal dysplasia Desbuquois dysplasia type 2, in which patients develop a progressive joint hypermobility and dislocatibility. Short stature is not necessary present in patients with spondylo-ocular syndrome due to homozygous mutations in XYLT2. Trunk height may be reduced but falls overall in the low-normal range. The inborn errors of the biosynthetic enzymes responsible for the GAG linkeropathies are summarised in Fig. 1. A second linkeropathy, spondyloepipmetaphyseal dysplasia with joint laxity (SEMDJL) (Beighton-type) was described by Beighton and Kozlowski ${ }^{[29]}$ in 1980. In a subsequent paper, $\mathrm{PB}^{[30]}$ reviewed the findings in a series of 18 cases followed for more than decade. Joint laxity was especially striking in the hands. Mutations in B3GALT6 result in a pleiotropic connective tissue disorder. ${ }^{[31]}$ Not only are features 


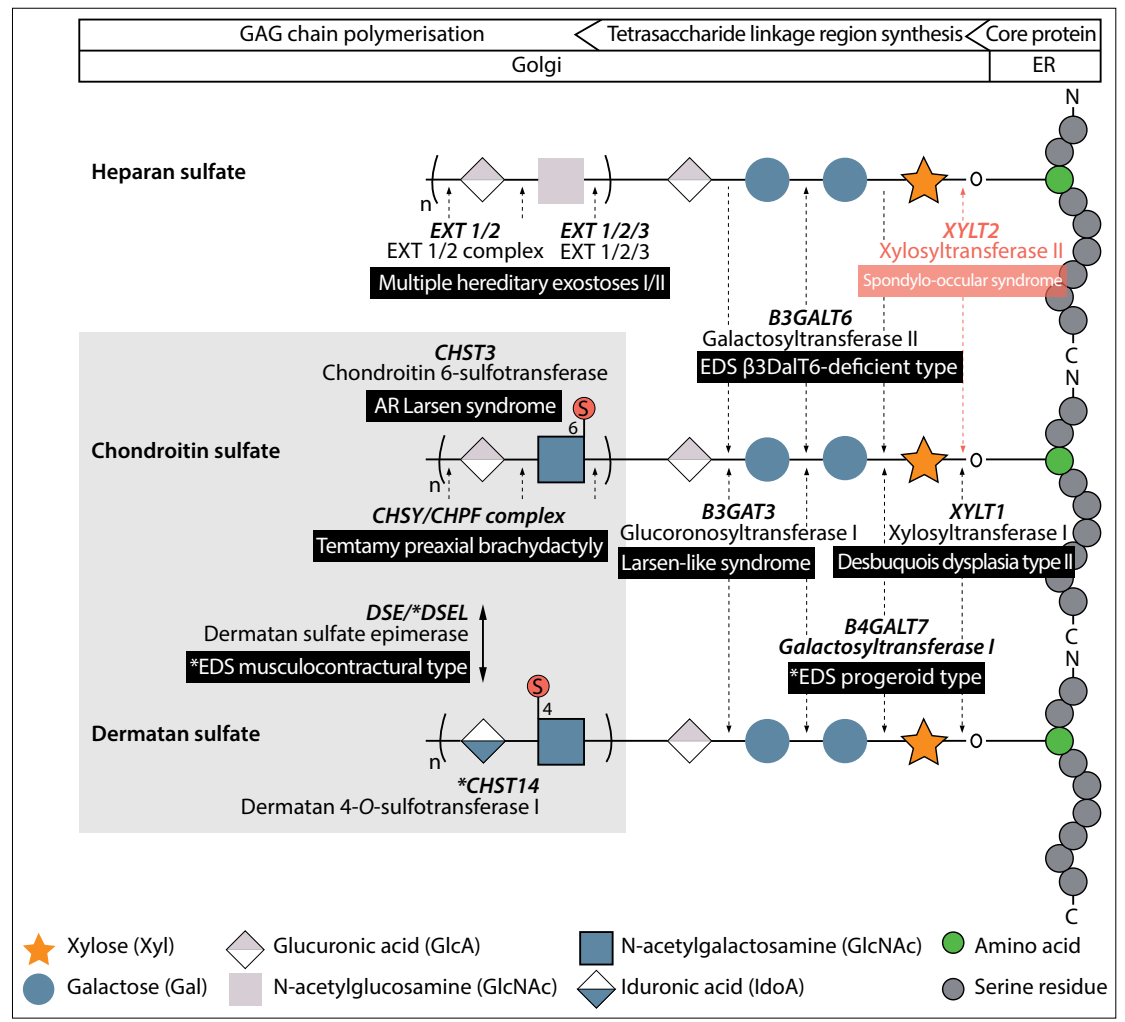

Fig. 1. The linkeropathies, modified after Fig. 1 in Malfait et al. ${ }^{[31]}$ (courtesy of Fransiska Malfait).

of joint hypermobility present, but there is a wide spectrum of findings including skin fragility, intellectual disability and a spondyloepimetaphyseal dysplasia with bone fragility. Kyphoscoliosis had been reported in the initial description, resulting in thoracic asymmetry, restrictive lung disease, respiratory failure and early death. PB subsequently reported that severe thoracic deformity was refractory to treatment and external bracing was usually ineffective. Survival beyond the early adult years was reduced.

Mutations in B4GALT7 (MIM 604327), a galactosyltransferase responsible for adding galactose to the O-linked xylose, results in a similar disorder to SEMDJL but with clinical features of EDS and premature ageing.

\section{Contributions of Africa and}

the Middle East to advancing

knowledge of genetic heterogeneity in $\mathrm{OI}$

More than any others, two papers have encouraged researchers to look beyond mutations in the two types I collagen genes as the cause of the clinical and radiographic heterogeneity in OI. These two papers by $\mathrm{PB}$ and colleagues have sustained research interest in pursuing molecular genetics studies in families in whom type 1 collagen mutations have been excluded either by linkage or by molecular DNA sequencing. ${ }^{[9,32]}$ In the second paper, $\mathrm{PB}$ and Versfeld noted the paradoxically high frequency of autosomal recessive OI type 3 in a hospital clinic survey of black patients with OI. While studies in hospital patients always run the risk of a major ascertainment bias, this sample is reflected in further studies in the southern African population indicating that autosomal recessive forms of OI are more common than the classic autosomal dominant OI type 1. BS has also been reported in high frequency in various tribes in southern African including the Tswana, Pedi and Shona tribe. Mutations in FKBP10 have been confirmed in patients with BS in the Venda tribe. ${ }^{[17]}$ FKBP10 is now the second-most common gene identified as a cause of OI in diverse populations. It was first localised and characterised as a cause of OI in the Turkish population. Common mutations are shared between the Arabian Peninsula and southern Africa. What was not understood initially is a considerable variability between and within families segregating mutations in FKBP10. Joint contractures may not be congenital but patients may still segregate osteoporosis and progressive pelvic deformity (progressive protusio acetabula). ${ }^{[21]}$ Furthermore, there may be very variable expressivity, with the first fractures occurring as late as the teenage years. Classic molecular genetic sequencing was used to define a common

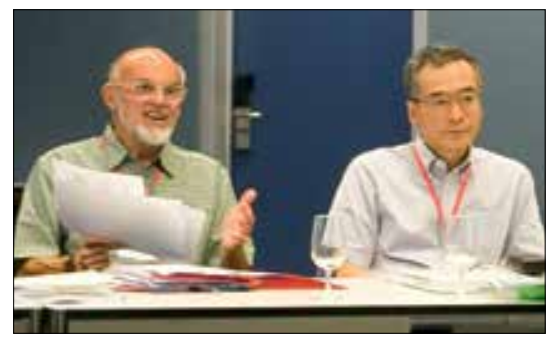

Fig. 2. PB contributing with Gen Nishimura to the discussion at the 5th International Nosology Meeting, ISDS, Martigny, Switzerland, 2005 (courtesy of Andrea Superti-Furga).

mutation in LEPRE1 in American blacks with origins in West Africa. This has led to confirmation of a raised heterozygous frequency for LEPRE1 mutation in those populations. ${ }^{[33]}$

\section{International conferences on the} nosology of constitutional disorders of the skeleton

An international nomenclature for constitutional (intrinsic) diseases of bone was convened as early as 1969 , following a meeting of paediatric radiologists in Warsaw. The initial committee meeting was held in Paris and presented its final report at the European Society of Paediatric Radiology in 1970. This became known as the Paris Nomenclature. Sufficient progress had been made by 1992 to convene a second revision which was attended by PB and 12 other experts. This second revision of the nosology grouped morphologically similar disorders, concluding that this classification would facilitate the recognition of specific entities. In setting out the international classification, the international working group on this occasion provided tabulation for mode of inheritance, chromosomal localisation, the responsible gene and the affected protein. ${ }^{[34]}$ Very little was known at the time; in fact, the genetic basis of only 30 of the 300 entities listed was known. This is in striking contrast to the report of the 2015 revision of the Nosology and Classification of Genetic Skeletal Disorders, where there are some 430 entities, of which 423 now have a known molecular genetic basis. ${ }^{[8]} \mathrm{PB}$ was also a founding member of the International Skeletal Dysplasia Society (ISDS) which held its first conference in the Children's Memorial Hospital, Chicago on 17 June 1993. His contribution to the delineation of the genetic skeletal dysplasias has been truly remarkable. At the first meeting of the ISDS he gave a presentation on 'Familial Hip Joint Dysplasia?. It must be very gratifying to him that the molecular defect in Beukes hip dysplasia was recently demonstrated to result 
Table 2. Genes in which mutations result in at least one type of OI (2015)

\begin{tabular}{|c|c|c|}
\hline \multicolumn{3}{|c|}{ Genes encoding type 1 procollagens and post-translational modifications } \\
\hline Gene symbol & Protein & Function (abbreviated) \\
\hline COL1A1 & Collagen 1 alpha 1 chain & Structural polypeptide \\
\hline COL1A2 & Collagen 1 alpha 2 chain & Structural polypeptide \\
\hline CRTAP & Cartilage-associated protein & Prolyl 3' hydroxylation \\
\hline LEPRE1 & Leucine proline-enriched proteoglycan (leprecan) 1 & Prolyl 3' hydroxylation \\
\hline$P P I B$ & Peptidylprolyl isomerase B & Prolyl 3' hydroxylation \\
\hline$P 4 H B$ & Prolyl 4' hydroxylase, beta-subunit & Prolyl $4^{\prime}$ hydroxylation \\
\hline PLOD2 & Procollagen lysyl hydroxylase 2 & Lysyl hydroxylation \\
\hline SERPINH1 & Serpin peptidase inhibitor, clade $\mathrm{H}$, member 1 & Collagen-specific ER chaperone \\
\hline SERPINF1 & Serpin peptidase inhibitor, clade F, member 1 & PEDF involved in osteoblast/osteoclast homeostasis \\
\hline FKBP10 & FK506 binding protein 10 & Type 1 procollagen chaperone \\
\hline$B M P 1$ & Bone morphogenetic protein 1 & C terminal cleavage, type 1 procollagens \\
\hline \multicolumn{3}{|c|}{ Genes encoding transcriptional regulator } \\
\hline CREB3L1 & OASIS & Unfolded protein response \\
\hline SEC24D & SEC24-related gene family, member D & Component of COP II machinery and transport of proteins through ER \\
\hline \multicolumn{3}{|c|}{ Genes encoding signalling process or signalling matrix } \\
\hline LRP5 & LDL-receptor-related protein 5 & WNT- $\beta$-catenin signalling pathway \\
\hline$W N T-1$ & Wingless-type MMTV integration site family, member 1 & WNT- $\beta$-catenin signalling pathway \\
\hline TMEM $38 B$ & Transmembrane protein $38 \mathrm{~B}$ & Calcium homeostasis in bone mineralisation \\
\hline PLS3 & Plastin 3 & Bone cell migration \\
\hline IFITM5 & Interferon-induced transmembrane protein 5 & Modulator of bone formation \\
\hline TGFBR1 & Transforming growth factor B receptor 1 & Central coordinator of coupled bone remodelling \\
\hline TGFBR2 & Transforming growth factor B receptor 2 & Central coordinator of coupled bone remodelling \\
\hline SP7/OSX & SP7 transcription factor (Osterix) & Osteoblast specific transcription factor \\
\hline \multicolumn{3}{|c|}{ Genes encoding matrix proteins or modifications } \\
\hline XYLT2 & Xylosyltransferase 2 & Tetrasaccharide linkage to proteoglycan core proteins \\
\hline
\end{tabular}

from mutations in the ubiquitin-fold modifier 1-specific peptidase 2 gene, UFSP2. ${ }^{[35]}$

PB made many contributions to the nosology meetings and the meetings of the ISDS. His contributions were highly respected by all. He made a memorable contribution to the meeting in Martigny in 2005 against the backdrop of the French Alps, contributing to the vigorous debate (Fig. 2).

Where are we now with OI? By 2015, it had been confirmed that there are three patterns of Mendelian inheritance - autosomal dominant, autosomal recessive and $\mathrm{X}$-linked recessive. The International Nomenclature Committee for Constitutional Disorders of the Skeleton has strongly proposed that, at the present time, the OI disorders be grouped into five major phenotypic groups (Table 1) known by characteristic names but also numbered by Arabic numerals. Twenty-two genes are now known in which mutations result in at least one of these five phenotypes (Table 2) or a special syndrome of OI plus other features. OI type 5, the disorder of OI with calcification of interosseous membranes, is the only one of the phenotypes at present known to result from mutations in just one gene, IFITM5.

Acknowledgements. The author acknowledges the long-term and sustained academic collegiality shared with himself and Dr Kazmierz Kozlowski. The author also acknowledges the contribution of the photograph of PB participating with Dr. Gen Nishimura in the committee work of the 5th International Nosology Meeting in Martigny (contributed by Prof. Andrea Superti-Furga). Fig. 1 was prepared by Dr Fransiska Malfait from Ghent, Belgium, and published here with her permission.

\footnotetext{
1. McKusick VA. Heritable Disorders of Connective Tissue. 4th ed. Saint Louis: The CV Mosby Company 1972

2. Beighton, P. The Ehlers-Danlos Syndrome. London: William Heinemann Medical Books Ltd, 1970

3. Seedorf K. Osteogenesis Imperfecta: A Study of Clinical Features and Heredity Based on 55 Danish Families Comprising 180 Affected Members. Copenhagen: Universitetsforlaget I Arhus, 1949

4. Smars G. Osteogenesis Imperfecta in Sweden. Clinical, Genetic, Epidemiological and Socio-medica Aspects. Stockholm: Scandinavian University Books, 1961.

5. Sillence D. Bone Dysplasia: Genetic and Ultrastructural Studies with Special Reference to Osteogenesis Imperfecta. Ann Arbor, USA: University Microfilms International, 1980.

6. Sillence DO, Senn A, Danks DM. Genetic heterogeneity in osteogenesis imperfecta. J Med Genet 1979;16(2):101-116. DOI:10.1136/jmg.16.2.101

Van Dijk FS, Sillence DO. Osteogenesis imperfecta: Clinical diagnosis, nomenclature and severity assessment. Am J Med Genet A 2014;164A(6):1470-1481. DOI:10.1002/ajmg.a.36545

Bonafe L, Cormier-Daire V, Hall C, et al. Nosology and classification of genetic skeletal disorders: 2015 revision. Am J Med Genet A 2015;167(12):2869-2892. DOI:10.1002/ajmg.a.37365

9. Wallis GA, Sykes B, Byers PH, Mathew CG, Vilioen D, Beighton P. Osteogenesis imperfecta type III: Mutations in the type I collagen structural genes, COL1A1 and COL1A2, are not necessarily responsible. J Med Genet 1993;30(6):492-496. DOI:10.1136/jmg.30.6.492

10. Beighton, P. Inherited Disorders of the Skeleton. Edinburgh: Churchill Livingstone, 1978.

11. Spranger JW, Langer LO, Wiedemann HR. Bone Dysplasias - An Atlas of Constitutional Disorders of Skeletal JW, Langer LO, Wiedemann HR. Bone Dysplas

(D) Beighton P, de Paepe A, Danks D, et al. International Nosology of Heritable Disordes
Tissue, Berlin, 1986. Am J Med Genet 1988;29(3):581. DOI:10.1002/aimg.1320290316

Tissue, Berlin, 1986. Am J Med Genet 1988;29(3):581. DOI:10.1002/ajmg.1320290316 N Engl J Med 2013;369(16):1529-1536. DOI:10.1056/nejmoa1308223

N Engl) Med 2013,36(16):1529-1536. DO1.10.1056/nejhoals08223 4. Hall JG. Review and hypotheses: Somatic mosaicism: Observations related to clinical genetics. Am Hum Genet 1988;43(4):355-363.

15. Sillence DO, Barlow KK, Cole WG, Dietrich S, Garber AP, Rimoin DL. Osteogenesis imperfecta type III. Delineation of the phenotype with reference to genetic heterogeneity. Am J Med Genet 1986;23(3):821-832. DOI:10.1002/ajmg.1320230309
} 
16. Horan F, Beighton P. Autosomal recessive inheritance of osteogenesis imperfecta. Clin Genet 1975;8(2):107-111. DOI:10.1111/j.1399-0004.1975.tb04398.x

17. Viljoen D, Versfeld G, Beighton P. Osteogenesis imperfecta with congenital joint contractures (Bruck syndrome). Clin Genet 1989;36(2):122-126. DOI:10.1111/j.1399-0004.1989.tb03174.x

18. Bank RA, Robins SP, Wijmenga $C$, et al. Defective collagen crosslinking in bone, but not in ligament or cartilage, in Bruck syndrome: Indications for a bone-specific telopeptide lysyl hydroxylase on or cartilage, in Bruck syndrome: Indications for a bone-specific telopeptide lysyl hydroxyla
chromosome 17. Proc Natl Acad Sci USA 1999;96(3):1054-1058. DOI:10.1073/pnas.96.3.1054

19. Van der Slot AJ, Zuurmond AM, Bardoel AF, et al. Identification of PLOD2 as telopeptide lysyl hydroxylase, an important enzyme in fibrosis. J Biol Chem 2003;278(42):40967-40972. DOI:10.1074/jbc.M30738020

20. Alanay Y, Avaygan H, Camacho N, et al. Mutations in the gene encoding the RER protein FKBP65 caus

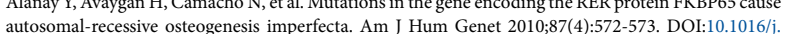
autosomal-recess

21. Schwarze U, Cundy T, Pyott SM, et al. Mutations in FKBP10, which result in Bruck syndrome and recessive forms of osteogenesis imperfecta, inhibit the hydroxylation of telopeptide lysines in bon

22. Collagen. Hum Mol Genet 2013;22(1):1-17. DOI:10.1093/hmg/dds 371
Shaheen R, Al-Owain M, Faqeih E, et al. Mutations in FKBP10 cause both Bruck syndrome and solated osteogenesis imperfecta in humans. Am J Med Genet A 2011;155A(6):1448-1452. DOI:10.1002/ ajmg.a.34025

23. Beighton P, Winship I, Behari D. The ocular form of osteogenesis imperfecta: A new autosomal recessive syndrome. Clin Genet 1985;28(1):69-75. DOI:10.1111/j.1399-0004.1985.tb01220.x

24. Frontali M, Stomeo C, Dallapiccola B, Opitz JM, Reynolds JF. Osteoporosis-pseudoglioma syndrome Report of three affected siblings and an overview. Am J Med Genet 1985;22(1):35-47. DOI:10.1002 ajmg. 1320220104

25. Beighton P. Osteoporosis-pseudoglioma syndrome. Clin Genet 1986;29(3):263.DOI:10.1111/.j.1399-0004.1986. tb00823.x

26. Schmidt H, Rudolph G, Hergersberg M, Schneider K, Moradi S, Meitinger T. Retinal detachment and cataract, facial dysmorphism, generalized osteoporosis, immobile spine and platyspondyly in a consanguinous kindred - a possible new syndrome. Clin Genet 2001;59(2):99-105. DOI:10.1034/j.1399-0004.2001.590206.x
27. Alanay Y, Superti-Furga A, Karel F, Tuncbilek E. Spondylo-ocular syndrome: A new entity involving the eye and spine. Am J Med Genet A 2006;140(6):652-656. DOI:10.1002/ajmg.a.31119

28. Munns CF Fahiminiya S, Poudel N, et al. Homozygosity for frameshift mutations in XYLT2 result in a spondylo-ocular syndrome with bone fragility, cataracts, and hearing defects. Am J Hum Genet 2015;96(6):971-978. DOI:10.1016/j.ajhg.2015.04.017

29. Beighton P, Kozlowski K. Spondylo-epi-metaphyseal dysplasia with joint laxity and severe, progressive kyphoscoliosis. Skeletal Radiol 1980;5(4):205-212. DOI:10.1007/bf00580591

30. Beighton P, Kozlowski K, Gericke G, Wallis G, Grobler L. Spondylo-epimetaphyseal dysplasia with joint laxity and severe, progressive kyphoscoliosis. A potentially lethal dwarfing disorder. S Afr Med J 1983;64(20):772-775.

31. Malfait F, Kariminejad A, Van Damme T, et al. Defective initiation of glycosaminoglycan synthesis due to B3GALT6 mutations causes a pleiotropic Ehlers-Danlos-syndrome-like connective tissue disorder. Am J Hum Genet 2013;92(6):935-945. DOI:10.1016/j.jhhg.2013.04.016

32. Beighton P, Versfeld GA. On the paradoxically high relative prevalence of osteogenesis imperfecta type III in the black population of South Africa. Clin Genet 1985;27(4):398-401. DOI:10.1111/j.1399-0004.1985.tb02282

33. Cabral WA, Chang W, Barnes AM, et al. Prolyl 3-hydroxylase 1 deficiency causes a recessive metabolic bone disorder resembling lethal/severe osteogenesis imperfecta. Nat Genet 2007;39(3):359-365. DOI:10.1038/ng1968

34. Spranger J. International classification of osteochondrodysplasias. The International Working Group on Constitutional Diseases of Bone. Eur J Pediatr 1992;151(6):407-415. DOI:10.1007/ bfol 059352

35. Watson CM, Crinnion LA, Gleghorn L, et al. Identification of a mutation in the ubiquitin-fold modifier 1-specific peptidase 2 gene, UFSP2, in an extended South African family with Beukes hip dysplasia. S Afr Med J 2015;105(7):558-563. DOI:10.7196/samjnew.7917

S Afr Med J 2016;106(6 Suppl 1):S13-S18. DOI:10.7196/SAMJ.2016.v106i6.11025 